\title{
Elégie Egyptienne pour la mère du silence
}

\author{
Mona Latif Ghattas
}

\begin{abstract}
Egyptian Elegy for the Mother of Silence
You sleep in your last bed sheltered by the earth as I keep you in the shadowy space of memory. You sleep the sleep of those who owe nothing more, you who made the sands glitter, who modestly, then wisely, limited your desires, you the very eloquence of silence awaiting in your old age only waves of love. I want to speak to you from the ocean depths, because I left the golden sands. I did not want to say goodbye when I took the boat to cross the ocean, so I missed your death, a missing that haunts me like a failed act, a ruse of destiny. So tonight, from the depths of the forest, I want to speak about you, remembering ... In exile, nothing dissolves the images of times past ... This litany of memories leads to the Nile which remains in me even when you mother of silence are no more. You the silence I hear behind my opaque veils, lead me to the light of equanimity. Nothing is lost in silence, I say to myself from time to time, as I advance in my exiles.
\end{abstract}

Le sable a dormi sur les monuments millénaires de Haute et de Basse Egypte.

Le soleil s'est couché derrière Khéops et la lune est montée sur la rive du Sphynx.

$C^{\prime}$ est le chant égyptien du jour et de la nuit.

Et maintenant tu dors

dans le dernier lit de bois que les arbres nous

donnent

la terre $\mathbf{t}^{\prime}$ abrite

comme je te garde dans l'espace ombragé

de mon souvenir.

Tu dors dans la sérénité légère de ceux qui ne doivent plus rien

tu as lustré tous les grains de sable du désert 
tu as nourri tous les moineaux

tous les ibis

les rossignols et les hiboux de nuit.

De toi je veux parler dans le silence

toi l'éloquence du silence

l'épopée

le conte magique du silence.

Toi qui avais en vérité tout au long de ta vie

limité tes désirs

par pudeur

enfin par sagesse

tu n'attendais dans la vieillesse

que les ondées d'amour.

Je veux parler de toi du fond de l'océan

carj'ai quitté les sables d'or sans vouloir te dire

adieu

sur des bateaux qui en ces temps larguaient au large

de l'Orient

attirant les passants vers les espaces d'Occident.

Sans vouloir te dire adieu et qui étais-je pour te

quitter ...

sur ces bateaux qui ne ramenaient pas

j'ai dû ainsi manquer ta mort

et ce manque me suit comme un acte manqué

comme une ruse du destin.

Alors ce soir du fond des bois

je veux parler de toi me souvenant

puisqu'en l'exil rien ne dissout les images d'antan.

Je me souviens de ces dimanches après-midi

quand nous étions seize petits

assis autour de toi

Téta la magnifique

assise sur le sofa du salon

près de cet homme qu'on appelait Guédo.

Téta et Guédo.

C'est ainsi que les enfants d'orient nomment leurs grands-parents. 
Assise à l'ombre de Guédo tu étais si grande à mes yeux d'enfant tu étais la puissance même et je croyais vraiment que tu savais changer le sable en or.

Tu parlais simplement comme parle la tendresse pure l'essence de l'amour.

Tu parlais peu comme ces êtres écoutants qui ne délient leur langue qu'en tout dernier recours quand les regards et les silences n'avaient pas su répondre.

Je me souviens de ce grand cadre doré accroché sur le mur du salon

face au sofa là où siégeait l'arbre généalogique de la famille portant les noms de toute la descendance mâle pour la postérité.

Je te demandais innocemment pourquoi mon nom n'y était pas inscrit

à la branche de mon père.

D'abord tu souriais timidement comme si je t'avais prise en faute. Et puis tu te levais comme une déesse antique me prenait par la main me conduisais vers la grande armoire en chêne qui couvrait le mur de ta chambre à coucher et tu ouvrait cérémonieusement le battant fermé à double tour.

Je pénétrais alors dans ton monde secret comme on pénètre en rêve dans la grotte d'Ali Baba. Parmi les boiseries les brocards et les coffrets pleins de bijoux mes yeux vagabondaient cueillant tous ces joyaux et je partais sur des chameaux aux selles roses à la conquête de mes désirs. Etj'entendais au loin ta voix 
glissant des mots marbrés

dont je n'ai retenu que la profonde essence

tu me disais en souriant

"Je te lègue tout cela".

Parler de toi je dois le faire dans la prière

car tu étais le rosaire des ronces

et la brise marine sur les chemins de croix

racine d'olivier

septième couche d'une Jérusalem enfouie.

Tu étais toutes les Marie

toutes les Madeleine

Rachel Ruth et Sarah

toi la Fertile

entre les mains de qui une poignée de farine pétrie pouvait nourrir un monde.

Car tu multipliais le moindre atome de bonheur

faisais surgir la parcelle d'espoir contenue dans

le chaos

prolongeais le souffle le plus fragile de la vie.

Tu étais la femme-serre

au sein de qui tout devait vivre

car tu ne blâmais jamais

pardonnant avant d'entendre

écoutant avant même qu'on ne parle

et ne parlant qu'à travers ton culte du silence pour

ne jamais blesser.

J'ai manqué ta mort

et ce manque me hante comme un acte manqué

j'aurai voulu que tu m'apprennes comment partir dans

la beauté.

Je n'ai pris part à aucune des veillées de ta nuit

car j'étais loin déjà

très loin dans l'océan

très loin du Nil

très loin de toi.

Alors

comme quand j'étais enfant 
le reste je l'imagine.

J'imagine la longue nuit

longue de quelques mois

où tu fus immobile sur un lit d'hôpital

transporté dans ta chambre afin de t'éviter de

changer de pays

afin de te garder près du vieil homme que tu servis

tout au long d'un chemin de fortune

pour qu'à son tour il te serve d'appui

près de cet homme que tu aidas

aux premières années de son jeune commerce

à teindre des mouchoirs de soie qu'il allait vendre

à la douzaine dans les souks du pays

et qui devint aussi par toi

l'homme puissant

qui te donna plus tard tant de bijoux

et cette tombe de marbre blanc comme le ciel de ton

coeur

comme le ciel de ciel de ton silence infini.

Moi j'imagine encore comment ce dernier soir passa

sur toi

passa sans moi.

L'air devait être un peu humide.

Grands et petits tour à tour ont dû faire la chaîne

pour te veiller de leur amour.

Ils étaient quinze à ton chevet

ils ont eu cet honneur.

Ce soir je te parle du fond des neiges

où quelquefois mes pieds pris dans la glace

gèlent mes gestes et mes élans.

Mais je voudrais $t^{\prime}$ offrir aussi

cette blancheur immaculée des paysages de mon exil

pour te dire que même la neige

te baise les mains.

Pour te dire que mon regard d'orient

trace et diffuse dans ces espaces

ton alphabet d'amour

ton concerto à mille voix 
et ton journal le plus intime.

Je t'imagine étendue sur un lit blanc un bateau blanc

une barque solaire comme celle des pharaons traversant le Fleuve sacré vers le royaume des morts et celui de la Vie. Je $t^{\prime}$ imagine flottant quelques jours sur le Nil atteignant l'autre rive et glissant dans l'éternité avec la même subtilité que ton passage dans la vie.

Quand tu passas resta le Nil.

Reste le Nil en moi sous les flocons pluvieux des exils de la terre.

Où que tu sois je te porte tout au long de ma vie de femme écorchée par la douleur du monde libérée par la puissance de ton éthique en moi Toi le silence que j'entends sous mes voiles souvent opaques et qui me mène vers la lumière d'un chemin équitable.

Chacune de nous sème en son temps.

Des grains germent quelquefois.

Demain des filles moissonneront.

Rien ne se perd dans le silence.

Je me le dis de temps en temps en avançant sur mes exils.

La neige a dormi sur les plaines du Nord.

Le soleil s'est levé sur le lac rond

de Sainte Adèle et la lune s'est couchée au sud de Vancouver. $C^{\prime}$ est le chant canadien du jour et de la nuit. 